\title{
Case Report: Persistent erectile dysfunction in a man with
}

\section{prolactinoma [version 1; peer review: 2 approved, 1 approved}

\section{with reservations]}

\author{
Justin Badal, Ranjith Ramasamy, Tariq Hakky, Aravind Chandrashekar, \\ Larry Lipshultz
}

Department of Urology, Baylor College of Medicine, Houston, TX 77030, USA

\begin{tabular}{l} 
V1 First published: 15 Jan 2015, 4:13 \\
https://doi.org/10.12688/f1000research.5743.1 \\
Latest published: 15 Jan 2015, 4:13 \\
https://doi.org/10.12688/f1000research.5743.1 \\
\hline
\end{tabular}

\section{Abstract}

Erectile dysfunction has been explored as a condition secondary to elevated prolactin; however, the mechanisms by which elevated prolactin levels cause erectile dysfunction have not yet been clearly established. We here present a patient with a history of prolactinoma who suffered from persistent erectile dysfunction despite testosterone supplementation and pharmacological and surgical treatment for the prolactinoma. Patients who have had both prolactinemia and erectile dysfunction have been reported in the literature, but we find no report of a patient with persistent erectile dysfunction in the setting of testosterone supplementation and persistent hyperprolactinemia refractory to treatment. This case provides evidence supporting the idea that suppression of erectile function occurs in both the central and peripheral nervous systems independent of the hypothalamic-pituitary-gonadal axis.

\section{Keywords}

prolactin, sexual dysfunction

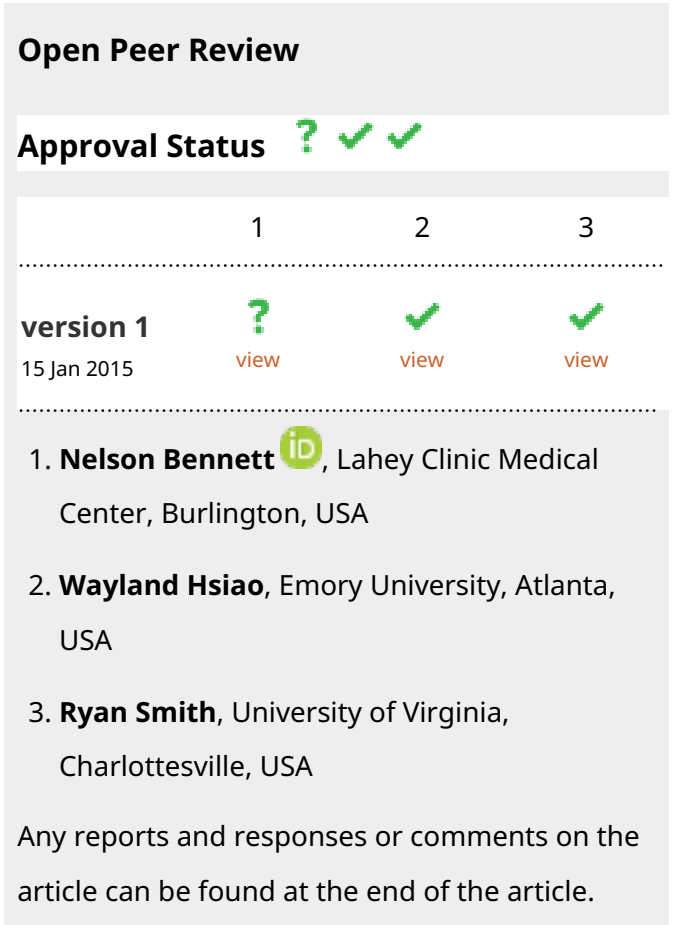

Corresponding authors: Ranjith Ramasamy (ranjithrama@gmail.com), Larry Lipshultz (larryl@bcm.edu)

Competing interests: No competing interests were disclosed.

Grant information: Ranjith Ramasamy is a K12 Scholar supported by a Male Reproductive Health Research Career Development Physician-Scientist Award (HD073917- 01) given by National institute of child health and development (NICHD)

Copyright: $\odot 2015$ Badal J et al. This is an open access article distributed under the terms of the Creative Commons Attribution License, which permits unrestricted use, distribution, and reproduction in any medium, provided the original work is properly cited. Data associated with the article are available under the terms of the Creative Commons Zero "No rights reserved" data waiver (CCO 1.0 Public domain dedication).

How to cite this article: Badal J, Ramasamy R, Hakky T et al. Case Report: Persistent erectile dysfunction in a man with prolactinoma [version 1; peer review: 2 approved, 1 approved with reservations] F1000Research 2015, 4:13

https://doi.org/10.12688/f1000research.5743.1

First published: 15 Jan 2015, 4:13 https://doi.org/10.12688/f1000research.5743.1 


\section{Introduction}

Prolactinomas are the most common type of pituitary adenoma and account for $30 \%$ of all clinically recognized cases of pituitary adenomas $^{1}$. Generally, prolactinomas arise in the second to fourth decade of life and are more quickly recognized in women than in men because the women experience an abrupt cessation of menses ${ }^{1-3}$. In men, hyperprolactinemia (HPRL) causes hypogonadotropic hypogonadism leading to decreased libido, impotence, infertility, gynecomastia or galactorrhea ${ }^{1,3,4}$. This effect is due to prolactin's inhibitory action on gonadotropin releasing hormone, which ultimately results in decreased luteinizing hormone levels and decreased testosterone production by the testes ${ }^{1,2,4}$.

\section{Case report}

The patient is a 23-year-old male who was seen initially in our clinic because of bilateral nipple discharge. His past medical history included a prolactinoma initially diagnosed when, at the age of 15 , he reported changes in his vision that were worst on the right side, with intermittent complete darkening. He was subsequently found to have a pituitary macroadenoma on imaging and a prolactin level of approximately $4000 \mathrm{ng} / \mathrm{ml}$. After therapy with cabergoline $0.5 \mathrm{mg}$, 3 times per week, his prolactin decreased to $30-40 \mathrm{ng} / \mathrm{ml}$, but there was no increase in testosterone. He was given supplemental testosterone therapy with testosterone cypionate. Three years after initial diagnosis, his prolactin levels had increased to $1500 \mathrm{ng} / \mathrm{ml}$, despite therapy with cabergoline.

He underwent transphenoidal resection 4 years after diagnosis (age 19) with removal of the sellar bulk of tumor, but with residual right cavernous tumor seen on post operative imaging. The prolactin levels decreased from 1500 to $300 \mathrm{ng} / \mathrm{ml}$, but continued to rise over the next few months despite therapy with cabergoline. Because of worsening symptoms a year later (age 20), he had gamma knife therapy of the residual right cavernous portion. However, prolactin remained elevated in the $500-600 \mathrm{ng} / \mathrm{ml}$ range, even though he was receiving cabergoline.

When he came to our clinic, he could not achieve an erection sufficient for masturbation or sexual activity, and he did not have nocturnal erections. With adequate testosterone supplementation and anastrazole therapy, he experienced increased energy levels and elevated libido and has expressed the desire for treatment for his erectile dysfunction.

\section{Clinical findings}

On physical examination, the patient was well developed and well nourished. His external chest exam was significant for gynecomastia despite recent bilateral mastectomy. The testes were $12 \mathrm{cc}$ in volume.

\section{Diagnostic assessment}

Hormone testing revealed a prolactin level of $300 \mathrm{ng} / \mathrm{ml}$ (normal range is $3.0-30.0 \mathrm{ng} / \mathrm{ml}$ ) while he was receiving therapy with cabergoline. Luteinizing and Follicle Stimulating Hormone remained low at all points during treatment ranging between 0.00 to $0.22 \mathrm{mIU} / \mathrm{ml}$ (normal range, $1.2-7.8 \mathrm{mIU} / \mathrm{ml}$ ) and 0.09 to $0.36 \mathrm{mIU} / \mathrm{ml}$ (normal range, 1.3 to $11.4 \mathrm{mIU} / \mathrm{ml}$ ), respectively. The patient's testosterone ranged from $384-1600 \mathrm{ng} / \mathrm{dl}$ (normal range of $200-1000 \mathrm{ng} / \mathrm{dl}$ ) while receiving testosterone supplementation with testosterone cypionate (200mg IM injection once a week initiated at the initial clinic visit).

\section{Therapeutic intervention}

A duplex penile ultrasound following injection of $0.30 \mathrm{cc}$ of TriMix demonstrated some engorgement of the patient's penis, with forty percent rigidity and no venous leak. Peak systolic velocity and end diastolic velocity were within normal limits. Despite treatment with tadalafil 5mg daily, he did not notice improvement in erectile function. He is now using a vacuum erection device for sexual activity. He was offered several different methods for improving his erectile function, including intracavernosal injections and an inflatable penile prosthesis and is currently debating which option to choose. Ultimately, the patient desires a more permanent solution to his erectile dysfunction, having stated that he is generally not satisfied with his current medical management for the erectile dysfunction. He notes that he is otherwise very pleased with the effects of the testosterone supplementation.

\section{Discussion}

In 2013, a published case study described a man with a pituitary adenoma who reported loss of libido and inability to have an erection over a period of 8 years ${ }^{5}$. All results of routine laboratory tests, including serum testosterone levels, were normal. Contrast MRI demonstrated a homogenous enhancement of the pituitary, and the patient was found to have a significantly elevated prolactin level. Despite normal testosterone levels, he had significant erectile dysfunction. After treatment with cabergoline, the patient achieved normal erectile function and improvement in neurologic symptoms. Similar to our patient, this patient had erectile dysfunction and hyperprolactinemia despite normal levels of testosterone, suggesting that prolactin has different ways of exerting its effect on erectile function.

The relationship between hyperprolactinemia and testosterone was first described in 1978 when a group of hypogonadal men with hyperprolactinemia were reported to have regained their sexual function only after receiving bromocriptine therapy, even though they had previously received adequate amounts of supplemental testosterone $^{6}$ (Figure 1). Another study in 2004 evaluated the effect of cabergoline on men with hyperprolactinemia and erectile dysfunction. The study measured episodes of nocturnal penile tumescence (NPT) and found that when hyperprolactinemic hypogonadic men were treated with cabergoline, the number of monitored erections during sleep (NPT) increased?

Unfortunately, there has been a misunderstanding of the hypothalamicpituitary-gonadal axis with regard to erectile function and prolactin. Elevated levels of prolactin lead to an impairment of the pulsatile release of luteinizing hormone resulting in decreased serum testosterone secretion. This hypogonadism was generally accepted as the main cause of erectile dysfunction. However, as we observed, despite adequate supplementation of testosterone as initial therapy for erectile dysfunction, the patient continued to be unable to have an erection. This mixed picture of elevated prolactin and "normal" testosterone raises the question of where prolactin is exhibiting its inhibitory effect.

Prolactin exerts its effects in a variety of locations, including the hypothalamus and the cavernosal bodies ${ }^{8}$. Hyperprolactinemia leads to increased expression of tyrosine hydroxylase mRNA in regions of the hypothalamus associated with sexual and erectile function. The fact that prolactin regulates the synthesis, release, and turnover of dopamine in hypothalamic neurons explains the initial increase 
in libido and erectile function observed in a study of male rats with acute hyperprolactinemia; however, a subsequent decrease in erectile function was observed as prolactin levels remained elevated, suggesting a down regulation of dopamine receptors secondary to chronically elevated levels of prolactin (Figure 2). This potential dysregulation of dopamine could explain the central inhibitory effect of hyperprolactinemia on erectile function, especially since erectile function has been shown to be corrected following bromocriptine administration before hypogonadism has been adequately treated. This evidence points to prolactin exerting its effect outside

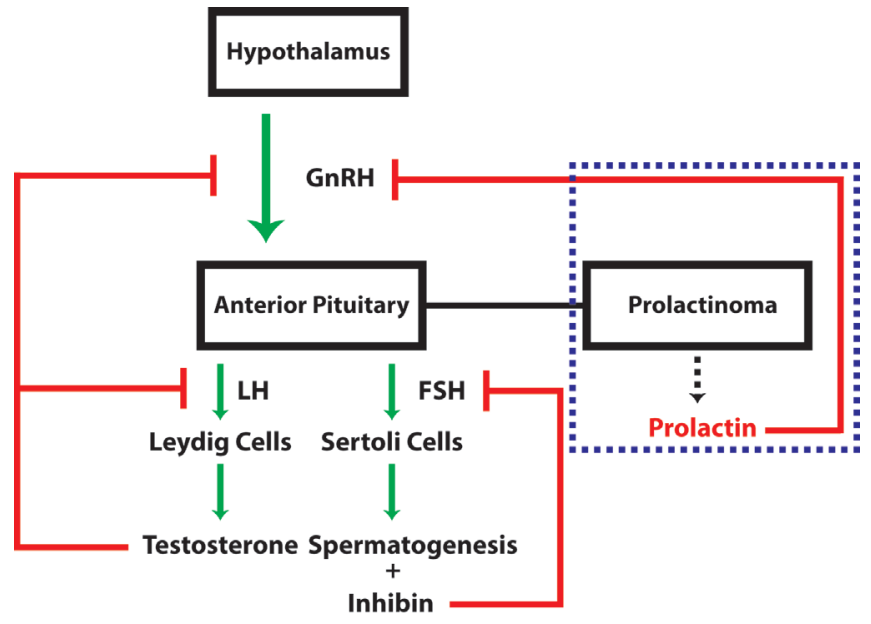

Figure 1. The normal hormonal axis regulating testosterone production. Gonadotropin releasing hormone (GnRH) stimulates release of Luteinizing Hormone (LH) and Follicle Stimulating Hormone (FSH) from the anterior pituitary which stimulates Leydig cells and Sertoli cells in the production of testosterone and sperm, respectively. Inhibin, produced by the Sertoli cells, negatively feeds back on FSH release from the anterior pituitary. Testosterone negatively feeds back on GnRH release from the hypothalamus and LH from the anterior pituitary, selfregulating its levels. In the dashed blue box, elevated prolactin secretion caused by a prolactinoma leads to pathologic inhibition of GnRH release from the hypothalamus and downstream inhibition of testosterone synthesis.
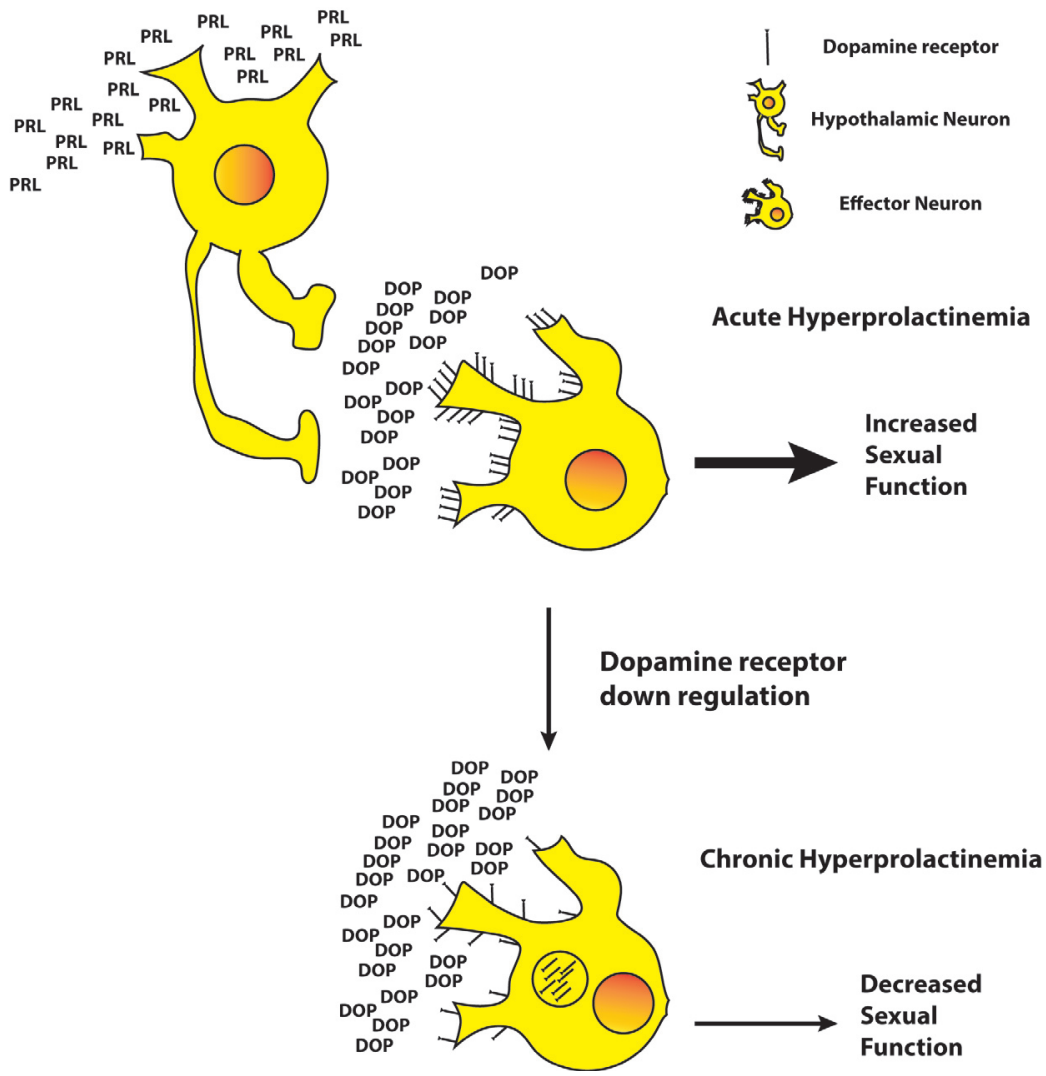

Figure 2. Schematic illustration of dopamine (DOP) receptor down regulation in a chronic hyperprolactinemia setting. Hypothalamic neurons are stimulated by chronically elevated levels of prolactin to excessively release dopamine which results in dopamine receptor internalization and dysregulation of the downstream signal for sexual function. 
of the hypothalamic-pituitary-gonadal axis and acting independently of depressed GnRH, LH, or testosterone levels.

Our patient had experienced a prolonged course of hyperprolactinemia and, with indicated treatment, did not adequately recover erectile function. Although the testosterone supplementation resulted in resolution of his other hypogonadal issues - namely loss of energy and mood swings - the elevated prolactin may have severely altered the excitatory pathways in the hypothalamus, necessitating longer term or more invasive treatment to ameliorate the offending suppression and erectile dysfunction.

\section{Consent}

Written informed consent for publication of clinical details was obtained from the patient.

\section{Author contributions}

JB wrote the draft of the manuscript. RR conceived the idea. TH and AC managed the patient and followed up with the patient. LIL provided overall supervision.

\section{Competing interests}

No competing interests were disclosed.

Grant information

Ranjith Ramasamy is a K12 Scholar supported by a Male Reproductive Health Research Career Development Physician-Scientist Award (HD073917- 01) given by National institute of child health and development (NICHD).
1. Kumar V, Abbas AK, Fausto N, et al:: Robbins \& Cotran Pathologic Basis of Disease, 8th Edition. Philadelphia: Saunders. 2009; 1103-4. Reference Source

2. Rogers A, Karavitaki N, Wass JA: Diagnosis and management of prolactinomas and non-functioning pituitary adenomas. BMJ. 2014; 349: g5390. PubMed Abstract | Publisher Full Text

3. Almalki $\mathrm{MH}$, Buhary B, Alzahrani S, et al:: Giant prolactinomas: clinical manifestations and outcomes of 16 Arab cases. Pituitary. 2014. PubMed Abstract | Publisher Full Text

4. Romijn JA: Chapter $\mathbf{1 3}$ - Hyperprolactinemia and prolactinoma. In: Eric Fliers MK and JAR, editor. Handbook Clin Neurol. Elsevier. 2014; 124: 185-95. PubMed Abstract | Publisher Full Text

5. Anand KS, Dhikav V: Hyperprolactinemia: an unusual cause of erectile dysfunction. Arch Sex Behav. 2013; 42(3): 341.

PubMed Abstract | Publisher Full Text

6. Carter JN, Tyson JE, Tolis G, et al:: Prolactin-screening tumors and hypogonadism in 22 men. N Engl J Med. 1978; 299(16): 847-52.

PubMed Abstract | Publisher Full Text

7. De Rosa M, Zarrilli S, Vitale G, et al:: Six months of treatment with cabergoline restores sexual potency in hyperprolactinemic males: an open longitudinal study monitoring nocturnal penile tumescence. J Clin Endocrinol Metab. 2004 89(2): 621-5.

89(2): $621-5$.
PubMed Abstract | Publisher Full Text

8. Walia R, Bhansali A, Dutta $P$, et al.: Recovery pattern of hypothalamo-pituitarytesticular axis in patients with macroprolactinomas after treatment with cabergoline. Indian J Med Res. 2011; 134(3): 314-9. PubMed Abstract | Free Full Text 


\section{Open Peer Review}

\section{Current Peer Review Status:}

\section{Version 1}

Reviewer Report 12 March 2015

https://doi.org/10.5256/f1000research.6139.r7928

(C) 2015 Smith R. This is an open access peer review report distributed under the terms of the Creative Commons Attribution License, which permits unrestricted use, distribution, and reproduction in any medium, provided the original work is properly cited.

\section{Ryan Smith}

Department of Urology, University of Virginia, Charlottesville, VA, USA

The authors have composed an excellent case report highlighting the fact that multiple mechanisms can impair erectile function. In addition, hormone replacement is not typically sufficient to resolve this issue. The pathophysiology behind the inhibitory effect of prolactin appears to extend beyond hypogonadism and is intriguing.

1. Do the authors have any IIEF/SHIM data at baseline and follow-up?

2. Perhaps the authors can comment on the use of TST as opposed to alternative agents (HCG) which would not impact fertility.

3. I would add some additional comments regarding the physical exam characteristics (i.e. secondary sex characteristics, etc.)

4. Do the authors have any conjecture as to the mechanisms underlying the impact of hyperprolactinemia on this patients ED despite TST?

Competing Interests: No competing interests were disclosed.

I confirm that I have read this submission and believe that I have an appropriate level of expertise to confirm that it is of an acceptable scientific standard.

Reviewer Report 25 February 2015

https://doi.org/10.5256/f1000research.6139.r7689

(C) 2015 Hsiao W. This is an open access peer review report distributed under the terms of the Creative Commons Attribution License, which permits unrestricted use, distribution, and reproduction in any medium, provided the original work is properly cited. 


\section{Wayland Hsiao}

Department of Urology, Emory University, Atlanta, GA, USA

This is an excellent case report that raises the idea that prolactin may have other mechanisms of action for suppression of erectile function besides the most commonly cited reason of low testosterone.

This case highlights the idea that there are certainly multiple mechanisms by which any biological alteration (high prolactin) can affect normal physiology (erectile function).

I would hope that the authors will comment on whether there are any plans to further intervene in this young man's prolactin beyond the already mentioned therapies. Also, for the evaluation of erectile function, more information could be given on the specific hemodynamic parameters obtained as well as any mention of what kind of baseline sexual function he has (either an IIEF score or other standardized questionaire).

However, overall, a great report to highlight that we don't understand all perturbation that go one when hormones are abnormal, and the "traditional" thinking of single pathways is probably folly and more a representation of reading about a disease in a textbook rather than critically thinking about the pathophysiology and the limitations of our current medical knowledge.

Competing Interests: No competing interests were disclosed.

\section{I confirm that I have read this submission and believe that I have an appropriate level of expertise to confirm that it is of an acceptable scientific standard.}

Reviewer Report 29 January 2015

\section{https://doi.org/10.5256/f1000research.6139.r7330}

(c) 2015 Bennett $\mathbf{N}$. This is an open access peer review report distributed under the terms of the Creative Commons Attribution License, which permits unrestricted use, distribution, and reproduction in any medium, provided the original work is properly cited.

\section{Nelson Bennett}

Institute of Urology, Lahey Clinic Medical Center, Burlington, MA, USA

This is an interesting case report involving a young man with persistent erectile dysfunction in the setting of a prolactinoma.

Introduction:

What are some of the actions of prolactin in normal male physiology?

Case Report:

The word "worst" is used inappropriately.

Why was a 15 year old male started on testosterone cypionate instead of HCG or other 
medications that would not compromise his fertility?

Are there plans for continued treatment of the prolactinoma?

Clinical Findings:

Please greatly expand this section. What are his vital signs, visual acuity, body habitus, body hair distribution, tanner stage, penile size, etc?

Diagnostic Assesment:

Aside from the prolactin, $\mathrm{LH}, \mathrm{FSH}$, and Testosterone levels, what is his TSH level and hematocrit level?

Therapeutic Intervention:

Was the duplex penile U/S completed in a multidosing regimen?

What were the actual duplex parameters..i.e. the PSV, EDV, and RI?

Discussion:

No issues, however, the integrity of the manuscript would be enhanced if the authors would offer suggestions on how to assess and treat these complex patients.

Competing Interests: No competing interests were disclosed.

I confirm that I have read this submission and believe that I have an appropriate level of expertise to confirm that it is of an acceptable scientific standard, however I have significant reservations, as outlined above.

The benefits of publishing with F1000Research:

- Your article is published within days, with no editorial bias

- You can publish traditional articles, null/negative results, case reports, data notes and more

- The peer review process is transparent and collaborative

- Your article is indexed in PubMed after passing peer review

- Dedicated customer support at every stage

For pre-submission enquiries, contact research@f1000.com 